\section{Testing the market}

Bryn Bridges

Mutagenesis. Executive editors J.M. Parry and J.A. Heddle. IRL. 6/yr. $\$ 145$ (institutional), $\$ 72$ (individual).

FOR many years, the induction of heritable changes in cells and organisms following exposure to radiations and chemicals was studied in a rather quiet academic manner. Then, in the early 1970s, it was realized that such changes were involved in the induction of cancer, and that agents able to cause them were many and widely distributed in our environment. The result was an explosion both of fundamental work and of the testing of substances for mutagenicity.

Any new publication in this field must compete with the outstandingly successful journal Mutation Research, which pioneered and now dominates it and which appears in six separate sections covering every aspect and featuring every type of paper. The appearance of Mutagenesis does not indicate the discovery of a niche unoccupied by the major journal but rather a frank determination to compete with it. Its success will therefore be determined by the factors of the market place. Is it of better quality, is it quicker to publish, is it better value for money?

On the evidence of four early issues, the standard of design and production is high, following the pattern of its stablemate Carcinogenesis which has successfully established itself in a field previously dominated by two other journals. Like Carcinogenesis, Mutagenesis has an American office and this has undoubtedly helped to establish a broad international character right from the outset. Thirtyone per cent of papers in the four issues I examined originated from Britain, 39 per cent from mainland Europe, 24 per cent from the Americas, and 6 per cent from Japan and China. Unlike Carcinogenesis, Mutagenesis is published for a learned society (the British Environmental Mutagen Society) and this has resulted in a high standard both of refereeing and of papers accepted.

In addition to original research papers, reviews and book reviews, there is a discussion forum in which controversial issues, particularly with regard to the regulatory use of mutagenicity tests, can be debated. A novel feature is the willingness of the publishers to store and make available on request laboratory data from extensive mutagenicity testing programmes, the conclusions of which are published only in summary.

It is not possible to give a realistic estimate of publication time based on the first few issues, when the receipt and publication pressures are not yet in equilibrium. If it follows the example of Carcinogenesis, however, the publication delay will be commendably brief.

The 1987 US subscription for Mutagenesis was $\$ 150$ compared with $\$ 1,992.50$ for its much larger competitor. I estimate

\section{Extra calcium}

\section{Iain MacIntyre}

Bone \& Mineral. Editor-in-chief D.V. Cohn. Elsevier. $8 / y r$ in two volumes. Dfl. 560 plus carriage charge.

Calcium metabolism in its clinical and physiological aspects is a major topic at endocrine meetings in the United States; for instance, at a recent get-together of the American Endocrine Society it provided the largest single sub-group of papers, even including neuroendocrinology. The American enthusiasm for this area is due in part to Fuller Albright's pioneering eminence in calcium metabolism as well as in endocrinology, and in part to the impact on health costs now being caused by osteoporosis.

In Britain, however, calcium metabolism is usually relegated to the tail end of a Friday afternoon. It is not at all surprising, therefore, that the appearance of still another calcium journal has been met on this side of the Atlantic more with grinding of teeth than acclamation.

The new journal is supported by an international group of scientists (International Conferences on Calcium Regulating Hormones) and has grown out of specialized conferences at first devoted only to parathyroid hormone. It is well produced and well edited, and although it hopes to cover a wider field, the important articles in the first few issues relate to clinical studies concerned with the treatment or prevention of osteoporosis.

It is rather doubtful whether the journal can carve a niche for itself in competition with Journal of Bone \& Mineral Research and other established journals such as Calcified Tissue. On the evidence of the first few issues, however, it may be successful because a number of articles will be consulted by groups in the expanding field of osteoporosis, while those in the calcium field in general will probably want to read it from time to time. I expect that the journal will survive and cover a more limited field than its present attempted compass. But the next few years will decide whether that survival is more than short-term.

Iain Maclntyre is Professor of Chemical Pathology at the Royal Postgraduate Medical School, Hammersmith Hospital, Du Cane Road, London WI2 OHS, UK. that Mutagenesis supplies nearly 4,000 words or word-equivalents per dollar, compared with less than 2,000 for Mutation Research.

It is already unthinkable for any worker in the field not to read Mutagenesis and the number of institutional subscriptions must be expected to rise sharply. Frugal librarians may then resort to a detailed consideration of whether one or more sections of Mutation Research could be dispensed with. It may well be that some rationalization of the latter's six sections may ensue, as well as a reappraisal of its overall competitiveness.

Bryn Bridges is Director of the Medical Research Council Cell Mutation Unit, University of Sussex, Falmer, Brighton BN1 9RR, UK.

\section{Improved access}

\section{D.C. White}

Japanese Anaesthesia Journals' Review. Chief editor T. Oyama. VNU. 4/yr. 257 DM.

AnAESTHETISTS attending international conferences on their speciality will have been aware for some time of an increasing volume of scientific work coming from Japan. They will also have appreciated that the language barrier is higher and more impenetrable in the case of Japanese than it is for the European languages. This is a major obstacle to the spread of information about Japanese work and is a handicap for Japanese workers.

Japanese Anaesthesia Journals' Review attempts to improve this situation and for that reason is to be welcomed. The journal has a Japanese editorial board together with a foreign editorial board of international flavour. Each number contains summaries of about 15 papers from the Japanese literature. Each of these is a rewritten version of the original paper condensed to three or four pages of excellent English with tables and diagrams. At the end of each summary four or five references are given under the heading "Related Literature". These references are almost entirely non-Japanese and in some cases are referred to in the text and in others not. This is an unsatisfactory feature - the work summarized is deprived of its context so that its significance (or otherwise) is obscured. Perhaps it is envisaged that reading the summary will send the reader to consult the original paper. In that case it would be helpful to know whether the original is written wholly in Japanese.

The papers chosen for inclusion are said to be from a wide range of Japanese anaesthesia journals, and seven are named as being surveyed. However, of the 61 papers covered in the first volume, 49 are 